\title{
Teaching EEG 3: Assessing the distribution of a paroxysmal activity
}

\author{
G.R.K. Sarma ${ }^{\text {a }}$, N. So ${ }^{b}$ \\ a Professor of Neurology, St. John's Medical College Hospital, Bengaluru, India \\ ${ }^{\mathrm{b}}$ Clinical Professor, Department of Neurology and Neurophysiology, Washington University Medical Center, Washington, USA
}

\section{Questions:}

1. The patient is a 7 year old boy. Describe the paroxysmal activity noted in $4^{\text {th }}, 6^{\text {th }}$ and $7^{\text {th }}$ seconds of this page.

2. What features warrant a re-assessment of its distribution?

3. Which other montage will be helpful in this situation?

\section{Answers:}

1. In this $\mathrm{Cz}$ referential montage, there is an intermittent, $5 \mathrm{~Hz}$ slow wave activity in $4^{\text {th }}, 6^{\text {th }}$ and $7^{\text {th }}$ seconds. On the first look, it appears to have a generalized distribution.
2. There are certain features that warrant a re-assessment of its distribution:

a. The waveforms in all the involved leads are monomorphic and "in-phase". In a referential montage, if there is an inphase, monomorphic activity in most leads, a contamination from the reference electrode needs to be considered.

b. The slow wave activity is seen in all the leads except C4, P4. A generalized slow wave activity without involving $\mathrm{C} 4$ and $\mathrm{P} 4$ is not physiologically plausible and may in fact suggest that $\mathrm{C} 4$, $\mathrm{P} 4$ and $\mathrm{Cz}$ are relatively equipotential.

3. To resolve this issue, a longitudinal bipolar montage was chosen (Fig. 2). In this montage, a slow wave activity involving only the

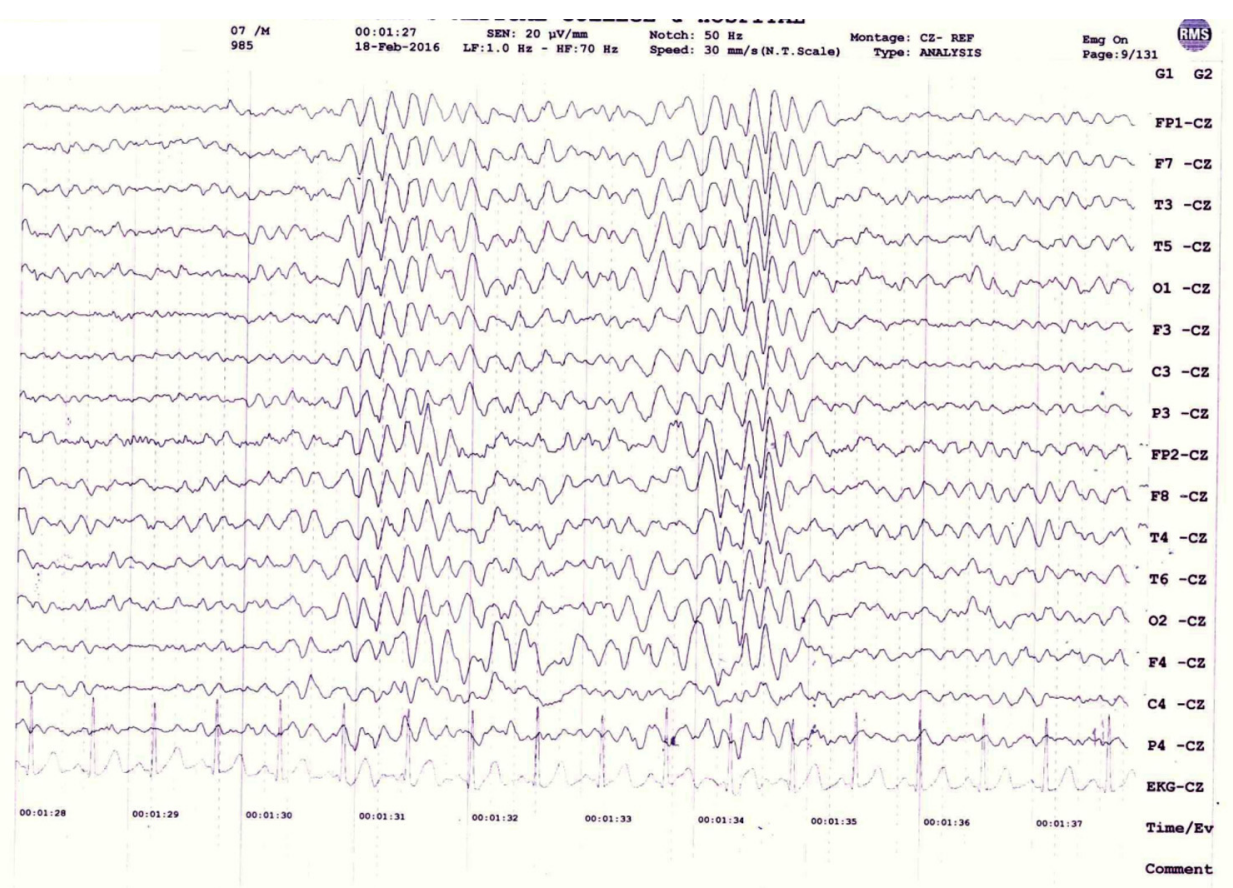

Fig. 1. Cz referential montage showing the paroxysmal activity in $4^{\text {th }}, 6^{\text {th }}$ and $7^{\text {th }}$ seconds. 


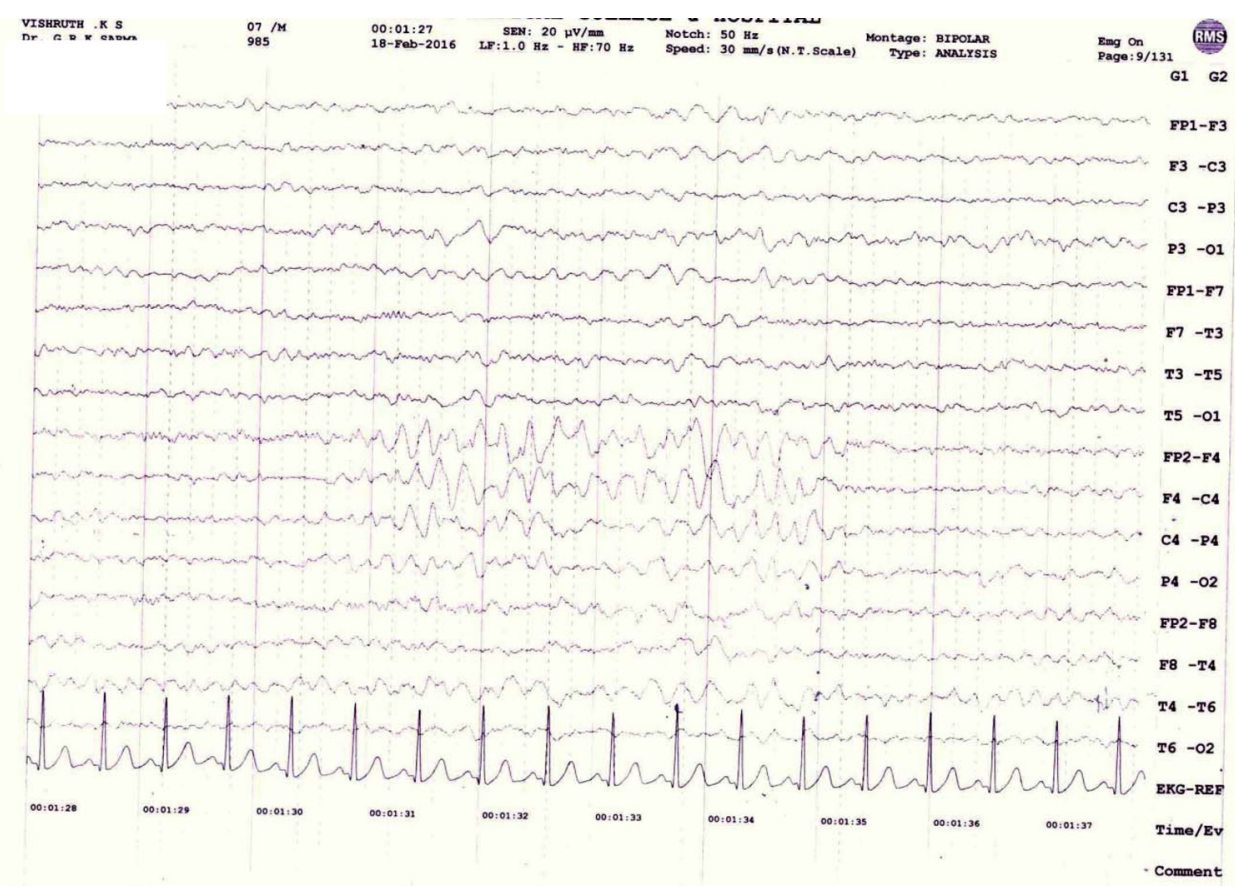

Fig. 2. Longitudinal bipolar montage showing the restricted distribution of the intermittent slow wave activity.

right frontocentral regions is obvious. In the $\mathrm{Cz}$ referential montage, the $\mathrm{Cz}$ electrode was involved in this slow wave activity and contaminated all the leads except C4 and P4 which were equipotential to $\mathrm{Cz}$.

Learning Point: In a referential montage, a generalized, inphase, monomorphic activity is likely to be due to a contaminated reference electrode.

\section{Acknowledgements}

We thank Mrs. Elizabeth VT, EEG technologist at St. John's medical college, Bengaluru for performing the EEG. 